\title{
Perkembangan Normal Tidur pada Anak dan Kelainannya
}

\author{
Dwi Putro Widodo, Taslim S Soetomenggolo
}

Tidur adalah keadaan fisiologis, merupakan kondisi istirahat reguler dengan karakteristik berkurangnya gerakan tubuh dan penurunan tingkat kesadaran terhadap sekelilingnya. Tidur tidak hanya merupakan sebuah keadaan tidak sadar yang berkepanjangan, ada pelbagai tahap yang dilalui sepanjang malam itu, yang masing-masing dapat diidentifikasi melalui aktivitas gelombang listrik otak. Tahapan tidur pada bayi dan anak dapat dikelompokkan menjadi, tidur aktif atau REM (rapid eye movement) dan tidur tenang atau non-REM. Tidur memegang peran yang sangat besar bagi perkembangan bayi. Pada saat inilah terjadi perbaikan sel-sel otak dan kurang lebih 75\% hormon tubuh diproduksi. Tidak ada bayi atau anak yang melewati masa kecilnya tanpa pernah mengalami gangguan tidur sama sekali. Gangguan tidur tidak hanya mempengaruhi bayi atau anak tersebut, tetapi juga dapat mempengaruhi seluruh keluarga, bahkan membawa dampak pada kehidupan bertetangga di sekitarnya.

Kata kunci: tidur, tahapan tidur, gangguan tidur

$\mathcal{9}$

sn't sleep wonderful! Anak kita mungkin lelah pada sore atau malam hari, dengan otot pegal dan kelopak mata mulai menutup, tetapi kita mengetahui pula bahwa anak ini akan bangun dengan ceria setelah mendapatkan tidur yang baik malam harinya. Tidur merupakan suatu cara untuk menggantikan tenaga yang hilang, cara mengisi kembali baterainya. Namun, tidak seorangpun mengetahui dengan pasti mengapa bayi, anak atau orang dewasa perlu tidur.

Tidur tidak hanya merupakan sebuah keadaan tidak sadar yang berkelanjutan, tetapi ada berbagai tahap yang dilalui sepanjang malam itu, yang masing-masing dapat diidentifikasi melalui aktivitas gelombang listrik di otak. Tidak ada bayi

Staf pengajar sub-bagian Neurologi Bagian Ilmu Kesehatan Anak, Fakultas Kedokteran Universitas Indonesia - Rumah Sakit Cipto Mangunkusumo Jakarta (Dr. Dwi Putro Widodo, SpA(K) dan Prof. Dr. Taslim S. Soetomenggolo, $\operatorname{SpA}(\mathrm{K})$ )

Alamat korespondensi:

Dr. Dwi Putro Widodo, Sp.A.

Bagian Ilmu Kesehatan Anak FKUI-RSCM, Jl. Salemba no. 6, Jakarta 10430. Tel.: 021-391 5665. Fax.: 3913982. atau anak yang melewati masa kecilnya tanpa pernah mengalami gangguan tidur sama sekali. Bagi sementara orang hal ini tidak pernah menjadi masalah. Mereka dapat mengatasi dengan baik gangguan tidur anak mereka. Mereka tidak merasa kuatir, tetapi kenyataannya tidak selalu mudah. Bagi banyak orang tua, bayi yang menjerit sepanjang malam adalah perkenalan mereka yang pertama dengan 'neraka dunia'. Gangguan tidur mempengaruhi seluruh keluarga, bahkan membawa dampak pada kehidupan tetangga di sekitarnya.

\section{Tidur Normal sebagai Fisiologi Dasar}

Tahapan tidur pada anak dan orang dewasa ternyata terdapat pula pada bayi baru lahir, yaitu tidur aktif atau REM (rapid eye movement) dan tidur tenang atau non REM. Pada bayi normal, anak dan orang dewasa mempunyai periode REM dan non REM yang berubah-ubah beberapa kali selama tidur malam hari. Pada tahun pertama, sebagian besar bayi terbangun pada malam hari, dan ini tidak diketahui 
oleh orang tuanya karena bayi biasanya tidak menangis.

Pada masa bayi terjadi beberapa perubahan, pola siklus tidur-bangun baru jelas terlihat pada umur 3-4 bulan, yaitu proporsi tidur lebih banyak pada malam hari. Umumnya morning naps berhenti pada umur 1 tahun dan afternoon naps terus berlangsung hingga umur 3 tahun. Pada akhirnya jumlah total tidur menurun bertahap selama periode anak-anak. Perkembangan tidur ini berkaitan dengan umur dan bertambah besarnya anak, maka jumlah tidur yang diperlukan berkurang dan diikuti dengan penurunan proporsi $R E M$ dan non REM. Dari rata-rata 16,5 jam pada umur 1 minggu, 14, 13, 12, 11 dan 10 jam pada umur 1, 2, 3, 5, dan 9 tahun (Gambar 1). tidur (sleep spindle). Pada tahap ini kedua bola mata berhenti bergerak dan tonus otot masih terpelihara. Selama waktu ini masih akan terbangun oleh suara yang agak berisik. Selama beberapa waktu berikutnya, masuk dalam tidur lelap tahap 3, dan bahkan tidur lebih lelap lagi pada tahap 4. Dalam tahap 3, orang yang tertidur cukup pulas, rileks sekali karena tonus otot lenyap sama sekali dan EEG memperlihatkan gelombang lambat delta 20-50\%. Tahap 4 adalah tidur paling nyenyak, tanpa mimpi dan sulit dibangunkan. EEG memperlihatkan dominasi gelombang delta (> 50\%) dan gelombang tidur sulit didapat. Ada yang mengatakan bahwa pada waktu ini, hormon pertumbuhan diproduksi untuk memulihkan tubuh, memperbaiki sel, membangun

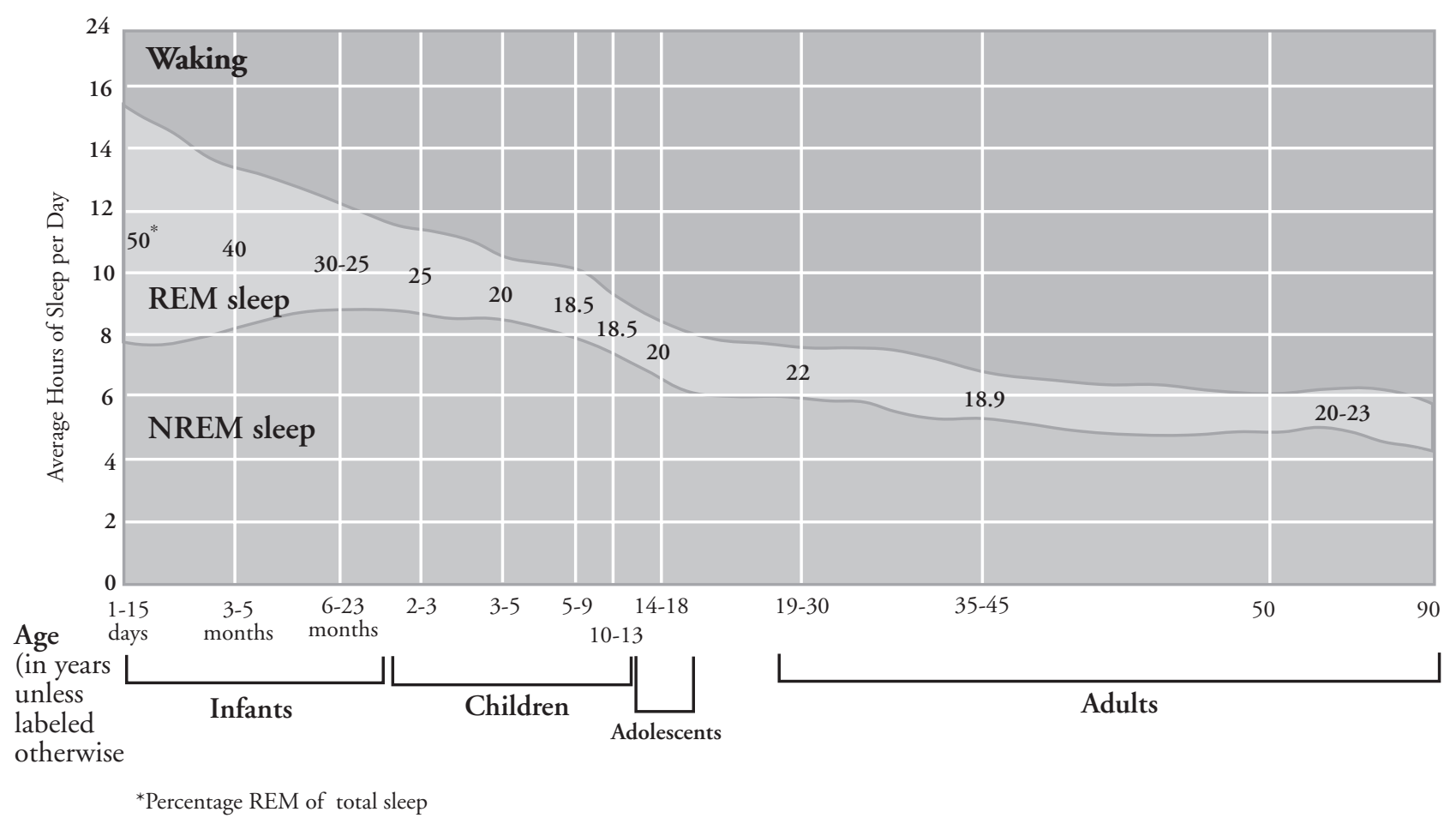

Gambar proporsi REM dan Non REM pada perkembangan tidak berdasarkan kelompok umur.

Perubahan-perubahan aktivitas korteks serebri selama tidur ternyata dikelompokkan dalam 5 tahapan tidur. Sewaktu siap untuk tidur, terbaring rileks, tonus otot mulai menurun dan mata masih terbuka, gelombang listrik otak memperlihatkan 'gelombang alfa' dengan penurunan voltase; keadaan ini sering disebut tahap 1 . Keadaan tidur masuk tahap 2, apabila timbul sekelompok gelombang berfrekuensi 14-18 siklus per detik, ini dinamakan gelombang otot dan jaringan pendukung, menguatkan tulang. Perasaan enak dan segar setelah tidur nyenyak ini setidak-tidaknya mungkin disebabkan karena hormon pertumbuhan bekerja baik.

Setelah berlangsungnya tahap 4, tiba-tiba bola mata mulai bergerak cepat, sehingga tidur ini disebut REM ( tahap 5). Detak jantung dan napas bertambah cepat, tekanan darah naik, otot-otot anggota gerak dan badan tegang kembali (menggerakkan badan di tempat tidur). 
Walaupun ada aktivitas demikian anak masih lelap tertidur dan sulit terbangun. Mimpi yang jelas terlihat pada tahap ini, dan ada yang mengatakan bahwa tahap tidur ini memulihkan pikiran, menjernihkan rasa khawatir dan mempertahankan sel-sel otak. Selama tahap tidur pertama sampai dengan tahap 4 kedua bola mata tidak bergerak secepat tahap tidur kelima. Olah karena itu jenis tidur selama keempat tahap itu dikenal sebagai non rapid eye movement sleep (nonREM)

\section{Mekanisme Fisiologi Tidur}

Tidur tidak dapat diartikan sebagai manifestasi proses deaktivasi susunan saraf pusat. Jadi seseorang yang tertidur bukannya karena susunan sarafnya tidak aktif, melainkan sedang bergiat. Tidur merupakan aktivitas area tertentu di otak yang menyebabkan tidur dan masukan sensorik yang menurun pada korteks serebri. Stimulasi pada area ini akan menghasilkan tidur, sebaliknya kerusakan akan mengakibatkan sulit tidur.

Siklus tidur-bangun dikontrol oleh reticular activating system (RAS). RAS terdiri dari sistem retikularis batang otak, hipotalamus posterior dan basal otak depan. Mekanisme tidur dan bangun ini sesungguhnya belum diketahui secara pasti. Aktivitas di pons, mid brain, dan hipotalamus posterior penting untuk keadaan bangun. Aktivitas di medula sangat penting untuk stimulasi keadaan tidur. Tidur dan bangun mungkin terintegrasi di basal otak depan.

Secara farmakologik, kini sudah ada bukti bahwa tidur non REM dibina oleh mekanisme serotoninergik dan REM dipelihara oleh mekanisme adrenergik. Sebagai contoh, pemberian serotonin dapat mengurangi latensi mula tidur secara bermakna, sebaliknya kerusakan area serotonin di pons akan menyebabkan insomnia. Sistem katekolamin (noradrenalin dan dopamin) juga mempunyai peran penting pada keadaan bangun dan tidur REM.

\section{Fungsi Endokrin Selama Tidur}

Siklus tidur mempunyai kaitan-kaitan dengan hormon tubuh, seperti hormon pertumbuhan, prolaktin, dan kortisol. Hormon pertumbuhan disekresi pada awal periode tidur lelap, tahap 3 dan 4 dan dihambat selama tidur REM, yang berhubungan dengan mimpi, dan prolaktin mencapai puncaknya antara jam 5.00 dan 7.00 pagi. Sekresi kortikosteroid yang biasanya terjadi selama malam hari, dapat berubah sesuai dengan siklus tidurbangun. Bila pola tidur berubah, sekresi kortisol pada awalnya seperti semula, tetapi secara bertahap melakukan penyesuaian atau resinkronisasi dengan siklus yang baru.

Fluktuasi hormon selama tidur bergantung pada 3 faktor utama, yaitu irama sirkadian, siklus bangun-tidur dan tahapan tidur non REM/REM. Penyebab variasi ini masih tanda tanya. Sekresi hormon kortisol dan adrenokortikotropik (ACTH) mengikuti irama sirkadian, dengan puncaknya pada pagi hari (6-8 jam tidur sampai 1 jam setelah bangun) dengan titik terendah pada larut malam. Thyrotropin-stimulating hormone juga berhubungan dengan irama sirkadian dengan puncaknya pada larut malam dan awal siklus tidur.

Meskipun puncak kadar aldosteron terjadi selama periode tidur lelap, namun tidak berkaitan secara spesifik dengan tahapan tidur non REM atau REM. Renin meningkat selama tidur tetapi menurun secara relatif selama tidur REM. Hormon pertumbuhan, prolaktin, luteinizing hormone ( $L H)$, dan testosteron berhubungan dengan tidur dan tahapan tidur. Kadar prolaktin pada laki-laki dan perempuan mencapai puncaknya selama siklus non REM, dengan titik terendah pada tidur $R E M$. Bila waktu tidur berubah maka kadar puncak prolaktin segera berubah pula dan mengikuti pola tidur yang baru.

Siklus sirkadian LH sangat berhubungan dengan tingkat maturitas seks pada kedua jenis kelamin. Pada anak prepubertal dan pubertal, sekresi LH meningkat selama periode tidur dan puncaknya terjadi pada periode tidur REM; oleh karena itu makin tinggi persentase tidur non REM akan makin rendah kadar LH.

\section{Gangguan Tidur}

Kekhawatiran orang tua terhadap pola tidur anak ternyata merupakan salah satu masalah yang sering dikonsultasikan kepada dokter anak. Mengingat cukup tingginya prevalensi gangguan ini, penting kiranya untuk diketahui dasar masalah ini dengan benar.

Secara garis besar ada 2 gangguan tidur yaitu disomnia dan parasomnia. Pada disomnia, gangguan terutama dalam kualitas, waktu atau lamanya tidur (sleep refusal dan night waking). Sebaliknya pada parasomnia, gangguan yang utama adalah adanya kejadian abnormal yang terjadi selama tidur, seperti night terrors, nightmares, sleep walking dan sleep talking. 
Insomnia, hipersomnia dan gangguan siklus tidurbangun (gangguan irama sirkadian) termasuk dalam disomnia. Nocturnal enuresis (bedwetting) yang terjadi pada 1/3 awal tidur dan sering dihubungkan dengan bangun pada malam hari juga dimasukan ke dalam gangguan tidur.

Klasifikasi gangguan tidur tersebut didasari suatu keadaan yang kronik, bukan gangguan sesaat yang merupakan bagian dari kehidupan. Gangguan tidur yang terjadi hanya beberapa malam setelah stress psikososial tidak didiagnosis sebagai gangguan tidur. Untuk membuat diagnosis gangguan tidur diperlukan paling sedikit 3 kali kejadian dalam seminggu dalam periode satu bulan dan disertai keluhan fisik seperti, kelelahan, irritable dan lain-lain.

Night terrors, nightmares, sleep refusal dan night waking merupakan keluhan orang tua yang paling sering dihadapi oleh dokter anak. Tinjauan ini tidak akan membahas masalah tidur pada anak yang jarang dijumpai, seperti narkolepsi, sleep apnea, atau sudden infant death syndrome.

\section{Prevalensi Gangguan Tidur}

Prevalensi gangguan tidur bervariasi tergantung pada jenis gangguan dan definisi yang digunakannya. Night waking didefinisikan sebagai bangun dan menangis 1 kali atau lebih antara tengah malam sampai - jam 5.00 pagi, paling sedikit 4 malam dalam seminggu atau 4 minggu sebulan. Kira-kira 25\% gangguan tidur terjadi pada bayi antara umur 6 bulan dan 12 bulan, prevalensi ini menjadi $50 \%$ pada bayi dengan ASI.

Suatu survai di masyarakat menunjukkan 20\% anak berumur 1 - 2 tahun bangun-malam sebanyak 5 kali atau lebih seminggu. Selama periode prasekolah $62 \%$ anak mempunyai pengalaman nightmares paling sedikit 1 kali dalam 2 minggu. Prevalensi ini meningkat dari 5\% pada umur 1 tahun menjadi 39\% pada umur 4 tahun. Sebaliknya hanya $6 \%$ anak dengan night terrors.

Night waking dan bedtime struggle cenderung menetap sampai diperlukan intervensi orang tua. Kebanyakan anak dengan gangguan ini pada umur 2 tahun akan berlanjut hingga umur 3 tahun. Sebaliknya night terror dan somnambulism (sleep walking) sering menghilang tanpa intervensi. Penanganan nightmares tergantung dari beratnya stress yang dialaminya dan keterampilan orang tua

\section{Night terrors (pavor nocturnus)}

Pada umumnya night terrors terjadi pada anak berumur 18 bulan -5 tahun. Anak yang sedang tidur tiba-tiba duduk, berteriak, tampak bingung, disorientasi, mata terbelalak, dan terlihat ketakutan sekali. Anak tersebut walaupun terbangun tetapi tidak mengenal orang tuanya atau orang lain. Serangan ini hanya berlangsung beberapa menit, kemudian anak tidur kembali, namun juga dapat berlangsung lama. Keesokan harinya sama sekali tidak ingat akan kejadian ini. Peristiwa ini terjadi biasanya setelah 4 jam pertama tidur malam yaitu pada periode tidur non REM. Sering kali orang tua mengira suatu nightmares; sebenarnya bukan, karena mimpi tidak terjadi selama periode non REM. Karena ini bukan mimpi, maka keesokan harinya anak tidak ingat kejadian yang mengerikan itu. Peristiwa ini terutama terjadi pada keadaan sedang sakit, stres, kurang tidur, namun dapat juga terjadi tanpa faktor stres yang jelas.

Penjelasan tentang fenomena ini kepada orang tua dan menyakinkannya bahwa anak akan baik, merupakan hal yang sangat penting. Perlu ditegaskan pada orang tua bahwa umumnya akan terjadi remisi spontan. Orang tua tidak dianjurkan membangunkan anak, tetapi membiarkan gangguan ini mereda dengan sendirinya. Bila tidak dibangunkan anak akan tidur kembali pada akhir episode serangan. Benzodiazepin dan antidepresi trisiklik dapat digunakan untuk keperluan sesaat pada night terrors dan sleep walking karena rebound efeknya.

\section{Somnambulism (tidur berjalan)}

Somnambulism sering terjadi pada anak besar atau remaja, antara umur 5 dan 7 tahun dan sering dijumpai riwayat keluarga dengan gangguan serupa. Anak bangun dari tempat tidur lalu berjalan, naik tangga, atau ke kamar mandi dengan mata terbuka, bahkan sampai keluar rumah yang dapat membahayakan hidupnya. Ia tidak dapat menjawab pertanyaan. Kejadian ini terjadi selama periode tidur non REM (fase sedang atau dalam). Pada anak tidur berjalan ini berhubungan dengan night terror dan ngompol. Umumnya serangan berlangsung sebentar selama beberapa menit, kemudian tertidur kembali. 


\section{Nightmares (mimpi buruk)}

Nightmares terjadi selama tidur REM. Paling sering terjadi pada anak berumur 4-6 tahun, meskipun studi membuktikan bahwa 25\% anak berumur 6-12 tahun masih dapat mengalami mimpi buruk. Anak bangun sepenuhnya dan tampak ketakutan. Biasanya dapat mengingat kembali isi mimpinya dan dapat ditenangkan oleh orang tua. Seperti night terrors, kejadian ini mudah timbul bila ada faktor stress. Mimpi buruk dapat disebabkan oleh berbagai faktor, dan beberapa di antaranya dapat dihindarkan misalnya makanan khusus pada malam hari, seperti coklat, keju dan coca cola; program televisi, dalam masa inkubasi penyakit, khawatir akan sesuatu. Sikap orang tua sebaiknya menenangkan dan mendampingi hingga anak itu rileks dan jangan memperlihatkan bahwa kita tegang. Yankinkan bahwa itu hanya mimpi, dan bukan kejadian yang sebenarnya. Sekarang telah aman dan mimpi telah selesai, biasanya anak akan segera tidur kembali. Proses ini akan cepat reda, bila situasinya berubah, misalnya dibawa ke toilet, ke ruangan lain untuk minum jus dan lain-lain. Bila kejadian ini berulang secara teratur, maka perlu diketahui latar belakangnya bila perlu mengkonsultasikan ke psikolog.

\section{Sleep Refusal (bedtime struggles)}

Anak sering kali menolak untuk tidur dengan cara menarik perhatian orang tua yaitu dengan meminta sesuatu berulang-ulang, seperti minum, pergi ke toilet, makanan, disebut sleep refused. Kadang kala mengatakan tidak mengantuk, sehingga orang tua sulit membedakan apakah ini suatu kenyataan, sikap menentang atau mencari perhatian orang tua saja.

Diagnosis hanya berdasarkan deskripsi dari masalah. Banyak faktor predisposisi yang perlu diperhatikan misalnya, tipe $O w l$, yaitu anak tidak mengantuk pada petang hari atau anak sudah terbiasa dengan problem tidur lambat. Catatan khusus (sleep $\log$ ) mengenai kegiatan tidur juga dapat membantu diagnosis dan sekaligus penatalaksanaannya.

Selain mengidentifikasi faktor predisposisi, penanganan problem ini terutama dengan memantapkan/menciptakan apa yang disebut dengan good sleep hygiene yaitu meliputi lingkungan tenang, cukup gelap dengan suhu yang nyaman, selain itu menciptakan waktu tidur yang rutin, anak diletakkan di tempat tidur sebelum tidur dan tidak mendapat paparan menakutkan atau aktivitas yang berlebihan 1 jam sebelum tidur. Cara ini sebaiknya dimulai sedini mungkin dan dapat mencegah atau merupakan penanganan utama dari gangguan tidur pada anak bila dikerjakan secara konsisten.

Bila anak mempunyai pola delayed sleep phase (gangguan irama sirkadian), maka siklus tidur anak harus disesuaikan dengan kebutuhannya dengan ketat. Jadwal ini akan merubah awal tidur 5-10 menit lebih awal setiap minggunya.

Bila sleep refusal ini merupakan bagian dari perilaku menentang, rekomendasi yang dianjurkan ialah meninggalkan kamar pada akhir jam tidur rutinnya dan mengabaikan tangisan dan kemarahannya. Bila anak keluar kamar, harus dikembalikan dengan tegas, dan hindari konversasi misalnya 'ini saatnya waktu tidur'. Dengan cara ini, dalam waktu 6 minggu terjadi penurunan yang signifikan baik frekuensi dan lamanya. Sebaliknya anak yang mempunyai rasa takut pada malam hari, meninggalkan kamar dan mengabaikan tangisannya akan memperburuk rasa takutnya. Meskipun kadangkala sulit membedakan apakah ini betul rasa takut atau hanya cara untuk menarik perhatian orang tua saja.

\section{Night walking}

Sebagian besar anak bangun pada malam hari, jika disertai tangisan yang lama dan kejadiannya berulangulang akan merupakan sumber stres bagi orang tua. Banyak faktor yang dapat membuat anak terbangun malam hari, seperti infeksi telinga. Namun umumnya anak dikonsultasikan ke dokter dengan masalah bangun malam berulang disertai tangis sehingga sulit untuk tidur kembali tanpa bantuan orang tua.

Penanganannya di antaranya dengan memberikan ketrampilan self-soothing sehingga tidak memerlukan orang tua. Selain dengan cara good sleep hygiene yang disebutkan di atas bila anak menangis pastikan bahwa tidak ada masalah fisik. Bila bayi berumur lebih dari 6 bulan dan biasa diberi minum pada saat itu, maka jumlahnya dapat dikurangi secara bertahap; hingga akhirnya tidak sama sekali dan diberikan hanya dalam keadaan bangun tidur. Membiarkan anak menangis dapat dibenarkan setelah yakin tidak terdapat gangguan fisik pada bayi tersebut, meskipun ada orang tua yang 
tidak ingin membiarkan anaknya menangis, karena akan menganggu anak yang lain.

Cara lain yaitu dengan prosedur membangunkan anak kira-kira 15-60 menit sebelum anak itu bangun spontan. Cara ini sama efektifnya dengan cara mengabaikan tangisan bayi, yang juga akan mengurangi bangun spontan secara bertahap. Obat sedatif seperti kloralhidrat, antihistamin seperti difenhidramin atau benzodiazepin jarang digunakan dan umumnya dalam beberapa hari saja.

Kadangkala orang tua mengeluh anaknya bangun terlalu pagi. Barangkali anak ini punya siklus tidurbangun tipe lark yang sudah mendapatkan cukup tidur dan bangun pada pagi dini hari. Bila anak tidur malamnya awal, mungkin anak mempunyai pola advanced sleep phase. Pada kasus ini, mula tidur dapat diubah agak lebih malam sehingga diharapkan anak akan bangun lebih siang tanpa mengurangi jumlah waktu tidurnya.

\section{Sleep paralysis (kelumpuhan waktu tidur)}

Sleep paralysis terjadi pada anak besar atau remaja. Serangan terjadi pada waktu anak baru saja tertidur, mendadak badan dan ekstremitas tidak dapat bergerak. Serangan berlangsung hanya beberapa detik, dan berakhir secara spontan, atau segera berakhir bila disentuh. Hampir semua orang pernah mengalami keadaan ini, seperti yang disebut sebagai ketindihan.

\section{Sleep starts (miyoclonus nocturnal)}

Miyoclonus nocturnal berupa serangan mioklonus atau mioklonik yang terjadi pada anak yang baru saja tertidur. Ini merupakan bentuk fisiologik mioklonus. Serangan ini bukan epilepsi dan tidak perlu pengobatan.

\section{Bed wetting (ngompol)}

Ngompol terjadi pada 1/3 awal tidur malam dan anak dapat bangun mendadak; hal ini dimasukkan sebagai gangguan tidur. Kontrol terhadap fungsi kandung kemih pada malam hari biasanya dicapai pada umur 3 tahun, sejumlah anak masih mempunyai kesulitan, misalnya 1 di antara 5 anak berumur 7 tahun masih ngompol, 1 di antara 14 anak berumur 10 tahun, dan 1 di antara 33 anak berumur 14-15 tahun tetap ngompol.

Pada umur enam bulan rata-tara ngompol setiap 2 jam dan popok sekali pakai yang berkualitas memiliki peran penting dalam membantu meningkatkan kualitas tidur bayi sepanjang malam, oleh karena itu jagalah agar bayi tetap kering sepanjang malam. Tidak seperti sleepwalking dan night terror, ngompol tidak berhubungan dengan tahapan tidur. Studi telah mengkonfirmasi bahwa anak berkemih terjadi pada setiap tahapan tidur, tidak selalu pada tidur dalam , tetapi lebih sering pada tahapan antara tidur dalam dan tidur ringan.

Terdapat 2 bentuk ngompol yaitu, primer dan sekunder. Bentuk primer dapat disebabkan oleh berbagai faktor misalnya, herediter, maturasi, latihan toilet yang kurang baik, dan problem saluran kemih. Bentuk sekunder umumnya disebabkan oleh stres. Penanganan umumnya dilakukan dengan 3 pendekatan yaitu, tanpa pengobatan, cara pendekatan perilaku, dan dengan pemberian obat.

\section{Konsekuensi Gangguan Tidur bagi Perkembangan Bayi}

Bagi bayi, tidur mempunyai arti yang lebih penting karena tidur memegang peran yang sangat besar bagi perkembangannya. Pada saat inilah terjadi perbaikan fungsi sel-sel tubuh termasuk sel otak dan diproduksinya hormon-hormon tubuh. Bayi dan anak yang tidak dapat tidur dengan baik akan menjadi overaroused dan sulit untuk memulai tidur. Defisit tidur yang berkepanjangan akan mengakibatkan iritabilitas, emosional dan kurang bergairah.

Pola tidur yang bervariasi pada anak merupakan hal yang biasa. Pola tidur yang tidak biasapun mungkin belum tentu menyebabkan suatu masalah, tetapi gangguan tidur sering menyebabkan stres yang bermakna bagi seluruh anggota keluarga dan membawa dampak yang tidak baik terhadap pendidikan anak dan pekerjaan orang tua.

Orang tua sering tidak mengetahui bahwa anak yang lelah itu menjadi iritabel, dan menangis merupakan petunjuk akan makin sulit baginya untuk tidur sehingga memerlukan intervensi orang tua. Ilmuwan telah membuktikan, bahwa: 
- Selama tidur terjadi perubahan fisik. Sebagai contoh, pupil menjadi kecil, pembentukan air liur, cairan pencernaan dan air seni menurun dengan drastis, denyut jantung menurun, volume udara bernafas berkurang, gambaran gelombang listrik otak melambat, dan kesadaran menurun atau menghilang.

- Tidur penting untuk kesehatan fisik dan mental. Anak yang tidak dapat tidur malam dengan baik akan menjadi irritable dan depresi, sulit mengerjakan sesuatu, dan sulit berkonsentrasi di sekolah. Dia mungkin kehilangan nafsu makan, berat badan menurun dan akhirnya jatuh sakit.

- Tidak seorangpun dapat bekerja tanpa tidur. Pada tahun 1986, seorang Amerika meraih world record karena melakukan sesuatu tanpa tidur selama 453 jam 40 menit, sementara dia hanya duduk di kursi goyang.

- Tidur membantu meningkatkan daya ingat.

- Telah diketahui secara umum bahwa tidur yang terganggu menyebabkan penurunan fungsi otak, meskipun bagian otak yang lain dapat mengkompensasinya.

\section{Daftar Pustaka}

1. Orr WC, Altshuler KZ, Stahl ML. Penyunting. Managing sleep complaints. Yearbook Medical Publish; 1982.

2. Blum NJ, Carey WB. Sleep problem among infants and young children. Pediatr rev 1996; 3:87-92.

3. Okawa M. Circadian rhythm sleep disorders. Asian Med J 2000; 43:235-42.

4. Harris JC. Sleep disorders. Dalam: McMillan JA, penyunting. Oski's Pediatrics principles and practice. Edisi ketiga. Philadelphia: Williams \& Wilkins; 1996:822-6.

5. Woolfson RC. A-Z of child development. Souvenir Press; 1993.

6. Harsono. Gangguan tidur. Buku ajar neurologi klinis. edisi pertama. Yogyakarta: Gajah Mada Press; 1999.

7. Said M. Pentingnya kualitas tidur bagi perkembangan bayi. Tanya jawab seputar perawatan dan perkembangan bayi. Tabloid Nakita, 2000; vol. 43, no.1. hal. 27.

8. Gilkin C. Brain can compensate for short-term sleep deprivation. Nature 2000; 403:655-7. 